\title{
Fuzzy utility models: possible applications in evacuation conditions in smart cities
}

\author{
M. L. De Maio \\ Dipartimento di Ingegneria dell'Informazione, delle Infrastrutture e \\ dell'Energia Sostenibile. DIIES, Università degli Studi Mediterranea di \\ Reggio Calabria, Italy
}

\begin{abstract}
In this paper the fuzzy utility models approach is proposed in relation to route choice in a network in evacuation conditions. Fuzzy logic is introduced and the main advantages are presented: the key concept of possibility allows a better representation of human minds. As a consequence, better results may be obtained in relation to users' behaviour representation. A possible application in evacuation conditions in a smart city is described.

Keywords: evacuation, smart city, fuzzy utility models, possibility, random utility models, route choice.
\end{abstract}

\section{Introduction}

Flows, travel times and congestion which occur on a transportation network depend on choices made by users. Generally users make their choices in an uncertain environment. In order to obtain a fair simulation of users' choices, several mathematical models where developed. Two main classes of models can be identified: Random Utility Models - RUM [1, 17] and Fuzzy Utility Models FUM [3, 4].

Many researchers, investigating the issue of choices on a transport system, used fuzzy logic and mathematics [3, 5-7]. The main difference which characterizes RUM and FUM is related to the way of representing uncertainty: in RUM uncertainty is expressed in terms of probability whereas in FUM uncertainty is expressed in terms of possibility $[3,4]$.

The main aim of this paper is to specify a mathematical model for route choice in evacuation conditions, in a smart city. Two mathematical formulations 
will be proposed: one using RUM and another using FUM. If the analyst is able to forecast users' behaviour, using a suitable model, he may design the network and introduce route guidance policy, in order to improve performances on the network. In this paper we do not want to state that FUM is better than RUM: we only aim at showing differences between them, advantages and disadvantages.

Four sections follow this introduction. Section 2 provides a general view about the state of the art on route choice. Section 3 summarizes RUM. Section 4 summarizes possible applications of FUM in a smart city in emergency conditions. Section 5 summarizes FUM and a model specification is proposed. Conclusions and further developments are put in section 6. In this paper all matrices, vectors and scalars related to RUM are characterized by an R as superscript else, if they are related to FUM, they are characterized by an F as superscript.

\section{State of the art}

In this section we are going to describe some of the works available in literature: the first part of this section is related to fuzzy logic applications and the second part deals with route choice simulation.

Non-RUM models where born after Zadeh proposed his fuzzy logic theory [8, 9]. Dubois and Prade proposed the possibility theory [10].

Fuzzy logic is used in many works about transportation system simulation: Atanu and Kumar [11] proposed an algorithm to solve the shortest path problem; Brito et al. [12] dealt with the distribution of frozen food using a fuzzy approach in order to obtain an optimal solution; Chang and Chen [13] deal with route choice using a user-optimal approach; Wang and Liao [14] solve a user equilibrium assignment problem.

Several applications of fuzzy logic in relation to choice dimensions are available in literature: for modal choice [7], route choice [3, 4, 6, 15]. Several researchers consider attributes represented by fuzzy numbers and users' behaviour based on the paradigm of rational user, as in RUM.

In relation to route choice simulation, it is worth underlying that models related to choice dimensions should be specified on three levels [16]: generation level, perception level, choice level.

In literature it is also possible finding approaches which simulate two levels instead of three levels: generation and perception levels are aggregated. In other works perception and choice levels are aggregated [17]. In the end some researchers consider a single level, aggregating generation, perception and choice [18].

Coming back to the three levels approach, we are going to describe simulation of each level. At the first level, alternatives are generated. Generation of alternatives can be carried out using different approaches: mono-set or multisets, exhaustive or selective, mono criteria or multi criteria. Alternatives generated compose the choice set or the choice sets. Each alternative which belongs to a choice set is characterized by a specific perception. Hence, at the second level, a perception probability is calculated [17, 19-21]. Perception 
probability is calculated using RUM or FUM. In the end, each alternative is characterized by a choice probability, calculated at the third level $[11,17,23-$ 25].

\section{RUM}

Random utility theory is the most consolidated theory available in literature for transportation systems simulation. According to RUM each decision maker, assigns to each perceived alternative, belonging to the choice set, a perceived utility $\mathrm{U}^{\mathrm{R}}{ }_{\mathrm{k}}$ which is a random variable, in order to take into account aspects not certainly known ([17]). $\mathrm{U}^{\mathrm{R}}{ }_{\mathrm{k}}$ is characterized by an expected value $\mathrm{E}\left(\mathrm{U}^{\mathrm{R}}{ }_{\mathrm{k}}\right)=\mathrm{V}^{\mathrm{R}}{ }_{\mathrm{k}}$, which is specified through some attributes $\mathbf{y}_{\mathbf{k}}^{\mathbf{R}}$ and some parameters $\boldsymbol{\beta}^{\mathbf{R}}$ and $\theta^{\mathrm{R}}$ :

$$
\mathrm{V}_{\mathrm{k}}^{\mathrm{R}}=v\left(\mathbf{y}_{\mathbf{k}}^{\mathrm{R}} ; \boldsymbol{\beta}^{\mathrm{R}} / \theta^{\mathrm{R}}\right)=\sum_{\mathrm{i}=1 . . \mathrm{N}}\left(\beta_{\mathrm{i}}^{\mathrm{R}} / \theta^{\mathrm{R}}\right) \cdot \mathrm{y}_{\mathrm{ik}}^{\mathrm{R}}
$$

In this paper we are focusing our attention on route choice and therefore we are interesting in the possibility to calculate route choice probability using RUM. In the following we are going to present some specification available in literature for route choice calculation like multinomial logit [11], nested logit [26], cross nested logit and link-nested logit [27], probit [28] and modified multinomial logit such as C-logit [21], DC-logit [21], path size logit [23] and mixed logit [17].

Being I the choice set, if $\mathrm{U}_{\mathrm{k}}^{\mathrm{R}}$ is independently and identically distributed (iid) according to a Gumbel random variable characterized by mean equal to $\mathrm{V}^{\mathrm{R}}{ }_{\mathrm{k}}$ and variance parameter $\theta^{\mathrm{R}}$, the multinomial logit model is obtained [2]:

$$
\mathrm{p}^{\mathrm{R}}(\mathrm{k} / \mathrm{I})=\left(\exp \left(\mathrm{V}_{\mathrm{k}}^{\mathrm{R}}\right)\right) /\left(\sum_{\mathrm{i} \in \mathrm{I}} \exp \left(\mathrm{V}_{\mathrm{i}}^{\mathrm{R}}\right)\right)
$$

The C - logit model specification (Russo et al. 2003):

$$
\mathrm{p}^{\mathrm{R}}(\mathrm{k} / \mathrm{I})=\left(\exp \left(\mathrm{V}_{\mathrm{k}}^{\mathrm{R}}+\mathrm{CF}_{\mathrm{k}}\right)\right) /\left(\sum_{\mathrm{i} \in \mathrm{I}}\left(\exp \left(\mathrm{V}_{\mathrm{i}}^{\mathrm{R}}+\mathrm{CF}_{\mathrm{i}}\right)\right)\right.
$$

In the $\mathrm{C}$-logit model, the introduction of the commonality factor $\mathrm{CF}_{\mathrm{k}}$ allows overcoming the independence of irrelevant alternatives (IIA), maintaining a simple mathematical formulation.

The Path Size model [23, 29]:

$$
\mathrm{p}^{\mathrm{R}}(\mathrm{k} / \mathrm{I})=\left(\exp \left(\mathrm{V}_{\mathrm{k}}^{\mathrm{R}}+\mathrm{PS}_{\mathrm{k}}\right)\right) /\left(\sum_{\mathrm{i} \in \mathrm{I}}\left(\exp \left(\mathrm{V}_{\mathrm{i}}^{\mathrm{R}}+\mathrm{PS}_{\mathrm{i}}\right)\right)\right.
$$

In the Path Size model, as in the C-logit, the correction term Path Size (PS) is introduced in the specification, in order to take into account overlapping of alternatives.

The link nested logit model [27]:

$$
\begin{gathered}
\mathrm{p}^{\mathrm{R}}(\mathrm{k} / \mathrm{I})=\Sigma_{\mathrm{l}}\left[\alpha _ { \mathrm { lk } } { } ^ { 1 / \mathrm { d } } { } _ { 1 } \operatorname { e x p } ( - \mathrm { x } _ { \mathrm { k } } / \varphi ) \cdot \left(\Sigma_{\mathrm{h} \in \mathrm{I}(\mathrm{l})} \alpha_{\mathrm{lh}}{ }_{1}^{1 / \mathrm{d}}{ }_{1}\right.\right. \\
\left.\left.\exp \left(-\mathrm{x}_{\mathrm{h}} / \varphi\right)\right)_{1}^{\mathrm{d}-1}\right] / \Sigma_{\mathrm{l}^{\prime}},\left(\Sigma_{\mathrm{h} \in \mathrm{I}\left(1^{\prime}\right)} \alpha_{\mathrm{lh}}{ }_{1}^{1 / \mathrm{d}}, \exp \left(-\mathrm{x}_{\mathrm{h}} / \varphi\right)\right)_{1^{\mathrm{d}}{ }^{-1}}
\end{gathered}
$$

In the link nested logit model, the choice set I is divided in subsets. 
Application of the link nested logit model reveals several limits. For example route choice probability depends on the number of links belonging to the considered route.

If random residuals are distributed with a multivariate normal random variable, characterized by zero mean and general variances and covariances, the probit model is obtained [30].

For RUM calibration, the method of Maximum Likelihood is used in many works.

\section{Possible application in evacuation conditions in a smart city}

In ordinary conditions both applications of RUM and FUM are available. In RUM users' uncertainty is represented by random residuals, whereas in FUM uncertainties are represented by possibility calculation. FUM applications are quite rare; on the contrary RUM use are consolidated.

In emergency conditions, a wide literature is available: travel demand during evacuation was treated in [31]; concerning transport supply, calibration of cost function was carried out in [32]; traffic assignment models in evacuation conditions and DSS for supply-demand interaction were dealt in [33] and [34]; in particular the issues of within-day traffic assignment and signal setting were addressed in [35]; specific attention was paid to path design form emergency vehicles and emergency vehicles routing [36-39]; the ITS may play a key role during an evacuation [40]; moreover, the planning process is dealt in [41, 42] and [43]; the issue of humanitarian logistics, particularly concerning relief vehicles is treated in [44]; moreover, carrying out training activities may improve evacuation planning and implementation [45].

A possible classification of path choice models in emergency conditions is proposed in [46]. Models applied in emergency conditions may be classified in relation to users' classes monoclass or multiclass) and instant of choice (pre-trip, en-route, hybrid). FUM applications in emergency conditions are quite rare. Sun et al. [47] dealt with the selection of the best path in emergency conditions considering four fuzzy factors in order to simulate users' choices. In relation to the same theme Wu et al. [48], proposed a Multi-target fuzzy decision-making mathematic model.

FUM keep some positive aspects of well-known RUM like simple mathematical formulation and easiness of calculation. One of the main differences between RUM and FUM is related to the main output: probability is the main output of RUM, possibility is the main output of FUM. It is worth noting that in situation characterized by lack of knowledge and high level of uncertainty, users will have a confused idea of alternatives and will associate to each of them a low value of possibility/credibility. This means that likely the sum of possibilities/credibilities will not be equal to one. In relation to this aspect, it is worth underlying that in RUM the sum of probabilities of alternatives belonging to the choice set has to be necessarily equal to one, whereas in FUM the sum of possibilities is not equal to one. In emergency 
situations, characterized by a very high level of uncertainty, confusion and quite completely absence of trustful information, possibilities may represent better than probabilities the way human mind works.

Efficacy of FUM application in evacuation conditions is a key issue to be investigated.

Recently, the definition of smart city spread up all over the world. According to the report "Smart cities - Ranking of European medium-sized cities" [49], smart cities definition is based on the definition of six dimensions:

1. Smart economy (Innovative spirit, Entrepreneurship, Economic image and trademarks, Productivity, Flexibility of labour market, International embeddedness, Ability to transform);

2. Smart mobility (Local accessibility, (Inter-)national accessibility, Availability of ICT-infrastructure, Sustainable, innovative and safe transport systems);

3. Smart environment (Attractivity of natural conditions, Pollution, Environmental protection, Sustainable resource management)

4. Smart people (Level of qualification, Affinity to lifelong learning, Social and ethnic plurality, Flexibility, Creativity, Cosmopolitanism /Openmindedness, Participation in public life);

5. Smart living (Cultural facilities, Health conditions, Individual safety, Housing quality, Education facilities, Touristic attractivity, Social cohesion);

6. Smart governance (Participation in decision-making, Public and social services, Transparent governance, Political strategies and perspectives).

In order to make smarter a city several actions should be introduced. Implementation of Information and Communication Technologies (ICTs) may help at reaching the general goal. For example this may help at providing information to users about the actual condition of the network and also may give the possibility to manage traffic providing specific route guidance to users. Many issues related to the kind of information to be provided and users' compliance to guidance should be investigated. It is worth underlying that only if intelligent systems are based on mathematical models which properly represent users' behaviour efficacy of actions implemented would be realized. The possibility to manage traffic in a smart city may lead to a smart mobility and this could allow rescuing many human lives in evacuation conditions.

\section{$5 \quad$ FUM}

Fuzzy model specification is based on the assumption that the generic user behave as a quasi-rational decision maker. Each user associates a utility $\mathrm{U}^{\mathrm{F}}$ to each alternative: $U^{F}$ is a fuzzy number characterized by a membership function $\mu_{U}$. The membership function $\mu_{U}$ may have values in the $[0,1]$ range. $U^{F}$ is characterized by a crispy part called $\mathrm{V}^{\mathrm{F}}$, specified through some attributes $\mathbf{y}^{\mathrm{F}}$ and some parameters $\boldsymbol{\beta}^{\mathbf{F}}$ and $\theta^{\mathrm{F}}$.

$$
\mathrm{V}^{\mathrm{F}}=\omega\left(\mathbf{y}^{\mathbf{F}} ; \boldsymbol{\beta}^{\mathrm{F}} / \theta^{\mathrm{F}}\right)=\sum_{\mathrm{i}=1 . . \mathrm{N}}\left(\beta_{\mathrm{i}}^{\mathrm{F}} / \theta^{\mathrm{F}}\right) \cdot \mathrm{y}_{\mathrm{i}}^{\mathrm{F}}
$$


Another specification of the crispy part $\mathrm{V}^{\mathrm{F}}$ is proposed in [50], where a commonality factor $\mathrm{CF}$ was introduced in order to take into account similarity between alternatives: the $\mathrm{C}$-fuzzy model is obtained.

The membership function $\mu_{U}$ numerically coincides with the possibility function [8]. For each alternative it is necessary calculating the possibility that the considered alternative has maximum utility: the possibility is obtained as the possibility of intersection between the perceived utility of the considered alternative and the maximum perceived utility, as expressed by (7).

$$
\operatorname{Poss}(\mathrm{k})=\operatorname{Poss}\left(\mathrm{U}^{\mathrm{k}} \geq \mathrm{U}^{\max }\right)
$$

From possibility it is possible obtaining probability of alternative k. A method to obtain a choice percentage distribution from possibility is proposed by Klir [51]:

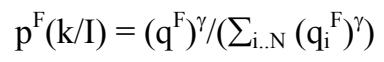

\subsection{Comparison between RUM and FUM}

In this section a comparison between RUM and FUM is proposed. At this aim a logit model (superscript L), belonging to the RUM family, and a fuzzy model are considered. First of all, RUM and FUM are characterized by a simple mathematical structure. For this reason, three different steps may be identified. It is worth noting that not all the three steps are available both in RUM and FUM. Anyway the logic process is the same for both FUM and RUM. First of all, the systematic utility has to be specified: at this aim attributes $\left(\mathrm{y}^{\mathrm{L}}-\mathrm{RUM} ; \mathrm{y}^{\mathrm{F}}-\right.$ FUM) and coefficients ( $\left.\beta^{\mathrm{L}}-\mathrm{RUM} ; \beta^{\mathrm{F}}-\mathrm{FUM}\right)$, to be calibrated, have to be used. The second step for FUM is the calculation of possibility: when a triangular distribution is chosen for the membership function, the calibrated parameters $\alpha_{1}$ and $\alpha_{2}$ and the scale parameter $\theta^{\mathrm{F}}$ are necessary for possibility calculation. This step is not present in RUM. On the contrary it is necessary in FUM in order to get the last step: the calculation of probability.

Probability is calculated both in RUM and FUM but different inputs are necessary: in RUM probability calculation appears $\mathrm{V}^{\mathrm{L}}$, the variance parameter $\theta^{\mathrm{L}}$; in FUM probability calculation appears the possibility $q\left(\mathrm{U}^{\mathrm{F}}\right)$ (obtained in the second step) and the scale parameter $\gamma$.

\subsection{2 Proposed FUM Specification}

In order to complete the specification of the fuzzy model the membership function distribution has to be chosen. In this paper we are going to choose a triangular distribution: $\mathrm{U}^{\mathrm{F}}$ is a fuzzy interval, characterized by a core value $\left(\mathrm{V}^{\mathrm{F}}\right)$ and two bounds, $U_{s}$ on the left and $U_{d}$ on the right (Figure 1). $U_{s}$ and $U_{d}$ are assumed to depend on two shape parameters $\alpha_{1}$ and $\alpha_{2}$. $U_{s}$ and $U_{d}$ are expressed as a function of $\mathrm{V}^{\mathrm{F}}$, through the shape parameters.

$$
\begin{gathered}
\mathrm{U}_{\mathrm{s}}=\alpha_{1} \mathrm{~V}^{\mathrm{F}} \quad \mathrm{U}_{\mathrm{d}}=\alpha_{2} \mathrm{~V}^{\mathrm{F}} \text { if } \mathrm{U}_{\mathrm{c}} \geq 0 \\
0<\alpha_{1}<1 ; \alpha_{2}>1
\end{gathered}
$$


The user perceives several alternatives. Each alternative is represented by a fuzzy interval as the one specified above. Amongst all the perceived alternatives, there is one alternative characterized by the largest perceived utility $U^{\max }$ (core value $\mathrm{V}^{\max }$ ). Moreover also the alternative chosen by the user is characterized by a fuzzy interval $\mathrm{U}^{\mathrm{SC}}$ (core value $\mathrm{V}^{\mathrm{SC}}$ ). In order to calculate the possibility, as explained in section 4 , it is necessary to identify an intersection between the triangular fuzzy distribution of the alternative characterized by the maximum utility $\left(\mathrm{U}^{\max }\right)$ and the triangular fuzzy distribution of the chosen alternative $\left(\mathrm{U}^{\mathrm{SC}}\right)$. If no intersections can be found the possibility is equal to zero. On the contrary, if there is an intersection, it is possible calculating it as follows:

$$
\begin{aligned}
\mathrm{y}=\mathrm{q}\left(\mathrm{U}^{\max }\right)=\mathrm{q}^{\mathrm{F}}= & \left(\left(\mathrm{U}_{\mathrm{C}}{ }^{\max } \cdot \alpha_{1}\right)-\left(\mathrm{U}_{\mathrm{C}}^{\mathrm{SC}} \cdot \alpha_{2}\right)\right) /\left(\left(\mathrm{U}_{\mathrm{C}}^{\mathrm{SC}} \cdot\left(1-\alpha_{2}\right)\right)\right. \\
& \left.-\left(\mathrm{U}_{\mathrm{C}}^{\max } \cdot\left(1-\alpha_{1}\right)\right)\right)
\end{aligned}
$$

For more detail about possibility calculation please see [50].

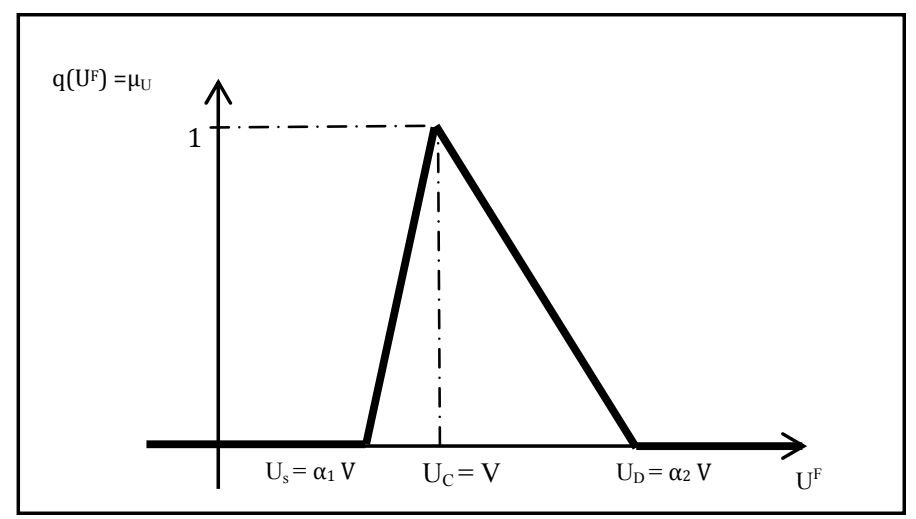

Figure 1: Graphical representation of the fuzzy number $U^{\mathrm{F}}=\left(\mathrm{U}_{\mathrm{s}}, \mathrm{U}_{\mathrm{c}}, \mathrm{U}_{\mathrm{d}}\right)$.

\subsection{Application on a test network}

The model proposed in section 6 is applied on a test network. Moreover also RUM described in section 3 are applied. In figure 5 the test network used for the application is presented: it is characterized by a single o-d pair, four links and three routes, indicated in Figure 2 as $\mathrm{a}, \mathrm{b}$ and $\mathrm{c}$.

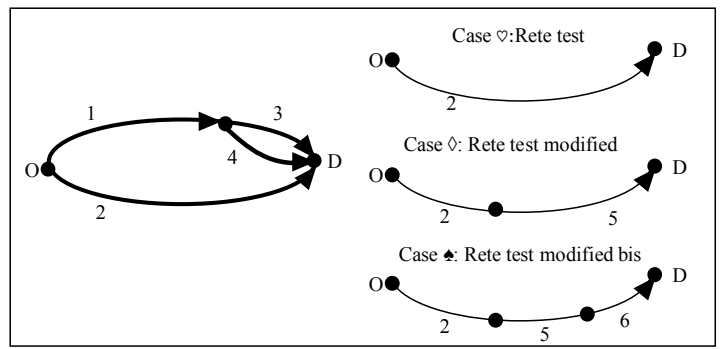

Figure 2: $\quad$ Test network. 
Please find the basic test network in Figure 2 indicated as the test network case $\odot$. Moreover a modified network is considered: it is obtained splitting link 2 in two parts by a new node. In the modified network all paths consists of two links. Please find the modified network in Figure 2 as case $\diamond$. In addition to this, a modified network bis is represented in Figure 2 and indicated as case $\mathbf{s}$ : it is obtained, splitting link 2 again by introducing another node. For links costs please see Table 1.

Table 1: $\quad$ Link - route incidence matrix for test network ${ }^{\mathrm{b}}$.

\begin{tabular}{|c|c|c|c|c|c|c|c|c|}
\hline Link & & & 1 & 2 & 3 & 4 & 5 & 6 \\
\hline \multirow{5}{*}{ Route } & \multirow[t]{3}{*}{$\mathrm{a}$} & Case 0 & 0 & 1 & 0 & 0 & & \\
\hline & & Case $\diamond$ & 0 & 1 & 0 & 0 & 1 & \\
\hline & & Case & 0 & 1 & 0 & 0 & 1 & 1 \\
\hline & $\mathrm{b}$ & & 1 & 0 & 1 & 0 & & \\
\hline & $\mathrm{c}$ & & 1 & 0 & 0 & 1 & & \\
\hline Link costs & & & $\mathrm{k}$ & 10 & $10-\mathrm{k}$ & $10-\mathrm{k}+\mathrm{h}$ & & \\
\hline
\end{tabular}

${ }^{6} 1=$ link belongs to the path; $0=$ link does not belong to the path.

In the following we are going to discuss results obtained applying models on the test network, represented in Figure 3.

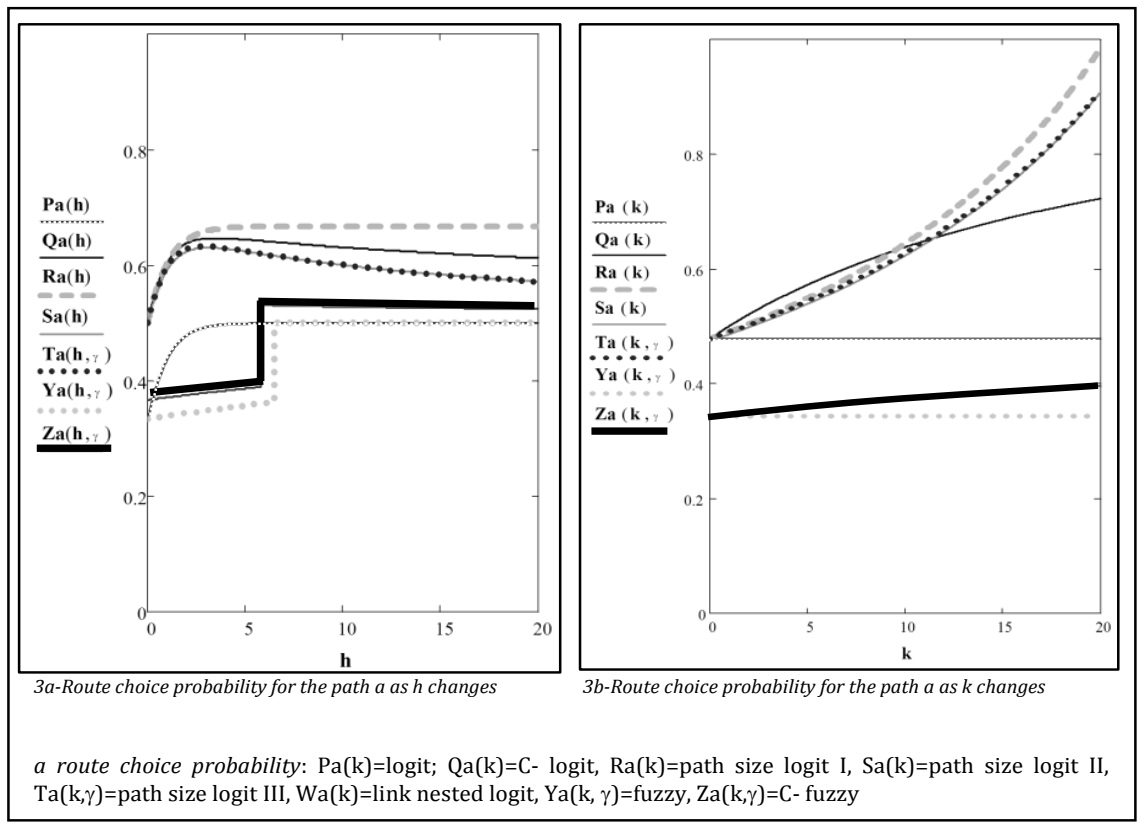

Figure 3: $\quad$ Route choice probability for path a. 
Figure 3 is composed of two figures. Figure 3a make us clearer the effect of changes in the value of $h$ on route choice probability of path a. On the contrary, figure $3 \mathrm{~b}$ make us clearer the effect of changes in the value of $\mathrm{k}$ on route choice probability of path a.

In figure $3 \mathrm{a}$, we can observe that if $\mathrm{h}$ is great, all models applied provide a probability equal to 0.5 . The main difference between figure $3 \mathrm{a}$ and figure $3 \mathrm{~b}$ is the jump which characterizes probability of $\mathrm{C}-$ Fuzzy in figure $3 \mathrm{a}$. This is because when possibility overcomes a limit (after which it would be negative that is impossible by definition) it is assumed equal to zero. On the contrary in figure $3 \mathrm{~b}$ there is no jump because the value of $\mathrm{k}$ does not influence route cost.

\section{Conclusions}

In this paper we proposed a specification for a fuzzy model and compared FUM and RUM. An application of the proposed model on a test network is presented. Moreover possible applications in evacuation conditions in a smart city are described in section 4. Considering the application on a test network, FUM are characterized by a simple mathematical formulation and calculation is not difficult. This makes FUM suitable for practical application.

Features of FUM described in this paper and results obtained from the application on a test network, suggest that FUM application may provide good results also in special context, for instance in evacuation conditions. In addition to this, intelligent systems available in a smart city, jointed with specific abilities of FUM to represent fuzziness in users' behaviour, may allow to realize good practices and lead to obtain good performances on the network, also in evacuation conditions. Uncertainty and lack of knowledge grow up in emergency conditions: therefore introducing possibility instead of probability, using FUM instead of RUM in emergency environments applications may lead to better results.

Delving into advantages and limits of the described methodology is necessary and for this reason the proposed model has to be applied in a real network. Calibration of parameters which characterize FUM and RUM has to be carried out.

\section{References}

[1] Domencich T. and McFadden D., Urban Travel Demand: A Behavioural Analysis. North-Holland, Amsterdam, 1975.

[2] Cascetta E., Transportation systems engineering: theory and methods. Kluwer Academic Publisher, Dordrecht, The Netherlands, 2001.

[3] Henn V., What is the meaning of fuzzy costs in fuzzy traffic assignment models? Transportation Research Part C 13, pp. 107-119, 2005.

[4] Henn V. and Ottomanelli M., Handling uncertainty in route choice models: From probabilistic to possibilistic approaches, European Journal of Operational Research, 175(3), pp. 1526-1538, 2006. 
[5] Lotan T., Modelling route choice behaviour in the presence of information using concepts of fuzzy sets theory and approximate reasoning. $\mathrm{PhD}$ thesis, Massachusetts Institute of Technology, Boston, MA, 1992.

[6] Russo F., Fuzzy Theory in Transportation Field: Fuzzy Sets for Simulating Path Choice Behaviour. In Morabito F.C. (ed.): Advanced in Intelligent Systems, IOS Press, 1997.

[7] Cantarella G.E. and Fedele V., Fuzzy utility theory for analysing discrete choice behaviour. In: Proceedings of the Fourth International Symposium on Uncertainty Modelling and Analysis, pp. 148-154, 2003.

[8] Zadeh L., Fuzzy sets. Information and Control 8(3), pp. 338-353, 1965.

[9] Zadeh L., Fuzzy sets as basis for a theory of possibility. Fuzzy Sets and Systems, pp. 3-28, 1978.

[10] Dubois D. and Prade H., Possibility theory. Plenum, New York, 1988.

[11] Atanu S. and Kumar P. T., Solving the Shortest Path Problem with Interval Arcs. Fuzzy Optimization and Decision Making, 5(1), pp. 71-89, 2006.

[12] Brito J., Martinez F. J., Moreno J. A. and Verdegay J. L., Fuzzy optimization for distribution of frozen food with imprecise times. Fuzzy Optimization and Decision Making, 11(3), pp. 337-349, 2012.

[13] Chang M.S. and Chen H.K., A fuzzy user-optimal route choice problem using a link-based fuzzy variational inequality formulation. Fuzzy Sets and Systems 114, pp. 339-345, 2000.

[14] Wang H.F., Liao H.L., User equilibrium in traffic assignment problem with fuzzy N-A incidence matrix. Fuzzy Sets and Systems, 107 (3), pp. 245-253, 1999.

[15] Ridwan M., Fuzzy preference based traffic assignment problem. Transportation Research Part C 12, pp. 209-233, 2004.

[16] Manski, The structure of random utility models. Theory and Decision 8, pp. 229-254, 1977.

[17] Cascetta E., Russo F., Viola F.A. and Vitetta A., A model of route perception in urban road networks. Transportation Research Part B, 36, pp. 577-592, 2002.

[18] Morikawa T., A hybrid probabilistic choice set model with compensatory and non-compensatory rules. In: Proceedings of the 7th WCTR, Sydney, Australia, 1996.

[19] Swait J. and Ben-Akiva M., Incorporating Random Constraints in Discrete Models of Choice Set Generation. Transportation Research B, 21B(2), pp. 91-102, 1987.

[20] Ben-Akiva M.E. and Boccara B., Discrete choice models with latent choice sets. In: International Journal of Research in Marketing 12, pp. 305-329, 1995.

[21] Russo, F. and Vitetta, A., An assignment model with modified Logit, which obviates enumeration and overlapping problems. Transportation 30, pp. 177-201, 2003.

[22] Antonisse R.W., Daly A.J. and Ben Akiva M.E., Highway assignment method based on behavioural models of car driver's route choice. Transportation Research Record 1220, pp. 1-11, 1985. 
[23] Ben-Akiva M. E. and Bierlaire M., Discrete choice methods and their applications to short term travel decisions. In R. Hall (ed.), Handbook of Transportation Science, Vol. 23 Kluwer, 1999.

[24] Polimeni A. and Vitetta A. Optimising waiting at nodes in time-dependent networks: cost functions and applications. Journal of optimization theory and applications, 156(3), pp. 805-818, 2013.

[25] Russo F. and Vitetta A., Reverse assignment: Calibrating link cost functions and updating demand from traffic counts and time measurements. Inverse Problems in Science and Engineering 19(7), pp. 921-950, 2011.

[26] Vovsha P., Cross-nested logit model: an application to mode choice in the Telaviv metropolitan area. In: Proceedings of the Annual Meeting of the Transportation Research Board, Washington DC, 1997.

[27] Vovsha P. and Bekhor S., The link-nested logit model of route choice: overcoming the route overlapping problem. Transportation Research Record 1645, pp. 133-142, 1998.

[28] Sheffi Y., Hall R. and Daganzo C., On the estimation of the multinomial probit model, Transportation Research A, vol. 16 (5-6), pp. 447-456, 1982.

[29] Frejinger E. and Bierlaire M., Capturing correlation with subnetworks in route choice models. Transportation Research Part B 41 (3), pp. 363-378, 2007.

[30] Daganzo C. F., Multinomial probit: the theory and its application to demand forecasting. Academic press, New York, 1979.

[31] Russo F. and Chilà G., Safety of users in road evacuation: Demand models. WIT Transactions on the Built Environment 96, pp. 773-782, 2007.

[32] Vitetta A., Musolino G. and Marcianò F.A., Safety of users in road evacuation: Calibration of cost functions and simulation. WIT Transactions on the Built Environment 101, pp. 715-725, 2008.

[33] De Maio M.L., Musolino G., Vitetta A, Traffic assignment models in road evacuation. WIT Transactions on Ecology and the Environment, 155, pp. 1041-1051, 2011.

[34] Vitetta A., Musolino G., Marcianò F.A., Safety of users in road evacuation: Modelling and DSS for transport supply and supply-demand interaction. WIT Transactions on Ecology and the Environment, 120, pp. 475-484, 2009.

[35] Marcianò F.A., Musolino G. and Vitetta A., Within-day traffic assignment and signal setting in road evacuation: A procedure with explicit path enumeration. WIT Transactions on the Built Environment 117, pp. 403414, 2011.

[36] Vitetta A., Quattrone A. and Polimeni A., Safety of users in road evacuation: Design of path choice models for emergency vehicles. WIT Transactions on the Built Environment 96, pp. 803-812, 2007.

[37] Vitetta A., Quattrone A. and Polimeni A., Safety of users in road evacuation: Modelling and DSS for paths design of emergency vehicles. WIT Transactions on Ecology and the Environment 120, pp. 485-495, 2009. 
[38] Polimeni A. and Vitetta A., Dynamic vehicle routing in road evacuation: Route design experimentation, WIT Transactions on the Built Environment 117, pp. 391-402, 2011.

[39] Polimeni A., The role of optimization models for rescue vehicles routes in evacuation. WIT Transactions on Information and Communication Technologies, 44, pp. 477-489, 2012.

[40] De Maio M.L., Musolino G., Vitetta A, The role of ITS in evacuation route choice. WIT Transactions on Information and Communication Technologies, 44, pp. 503-515, 2012.

[41] Russo F. and Rindone C., Safety of users in road evacuation: Planning internal processes and guidelines. WIT Transactions on the Built Environment 96, pp. 825-834, 2007.

[42] Russo F. and Rindone C., Safety of users in road evacuation: Modelling and DSS for LFA in the planning process. WIT Transactions on Ecology and the Environment, 120, pp. 453-464, 2009.

[43] Russo F. and Rindone C., Data Envelopment Analysis (DEA) for evacuation planning. WIT Transactions on Information and Communication Technologies, 43(PART I), pp. 455-467, 2010.

[44] Russo F. and Trecozzi M.R., Models for humanitarian logistics. WIT Transactions on Ecology and the Environment 155, pp. 1079-1089, 2011.

[45] Russo F., Rindone C. and Trecozzi M.R., The role of training in evacuation. WIT Transactions on Information and Communication Technologies, 44, pp. 491-502, 2012.

[46] De Maio M. L., The role of path choice and traffic assignment models in evacuation, WIT Transactions on Information and Communication Technologies, 44, pp. 465-476, 2012.

[47] Sun X. and Lu J., A method of emergency logistics route choice based on fuzzy theory. Proceedings of ICLEM 2010: Logistics For Sustained Economic Development: Infrastructure, Information, Integration, 2010.

[48] Wu Q., Chen T. and Su Y., The Best Path Analysis Based on Multi-target Fuzzy Decision-making. Computer simulation 22(12), 106-109, 2005.

[49] Giffinger R., Christian F., Hans K., Robert K., Nataša P.-M., Evert M., Smart cities - Ranking of European medium-sized cities. http://www.smartcities.eu/. Vienna: Centre of Regional Science, 2007.

[50] Quattrone A. and Vitetta A., Random and fuzzy utility models for road route choice. Transportation Research Part E: Logistics and Transportation Review, 47(6), pp. 1126-1139, 2011.

[51] Klir G. J., A principle of uncertainty and information invariance. International Journal of General Systems n.2/3, pp. 249-275, 1990. 